\title{
Influence of the Double Bond LDH Clay on the Exfoliation / Intercalation Mechanism of Polyacrylamide Nanocomposite Hydrogels
}

\author{
IONUT CRISTIAN RADU ${ }^{1}$, EUGENIU VASILE ${ }^{2}$, CELINA MARIA DAMIAN $^{1}$, HORIA IOVU $^{1}$, PAUL OCTAVIAN STANESCU ${ }^{1}$, \\ CATALIN ZAHARIA ${ }^{1 *}$ \\ ${ }^{1}$ University Politehnica of Bucharest, Advanced Polymer Materials Group,1-7 Gh. Polizu Str., 011061, Bucharest, Romania \\ ${ }^{2}$ University Politehnica of Bucharest, 313 Splaiul Independentei Str., 060042, Bucharest, Romania
}

\begin{abstract}
The paper focuses on the obtaining of novel nanocomposite hydrogels based on polyacrylamide and layered double hydroxides (LDHs) modified with double bonds. The modification of LDH clay was investigated by FTIR, X-ray photoelectron spectroscopy (XPS) and X-ray diffraction (XRD) analyses. Mechanical properties of the nanocomposite hydrogels were employed by compression and rheological measurements. The formation of exfoliated and intercalated structures was evidenced in transmission electron microscopy (TEM). Chemical cross-linking of hydrogels using both classical cross-linker and modified clay was an efficient method to improve the mechanical properties of novel nanocomposite hydrogels. These hydrogels with improved mechanical properties could be further tested for biomedical applications such as tissue engineering.
\end{abstract}

Keywords: nanocomposite, clay, hydrogels, cross-linking, exfoliation/intercalation

Polymeric hydrogel nanocomposites based on inorganic clays are a growing research field due to their potential for biological applications [1-4]. Hydrogels can swell high amount of water or aqueous solutions and behave like soft materials. Recently, there were developed smarthydrogels capable of stimuli-response for tissue engineering or systems for controlled drug release [5-12]. In case of applications that require increased mechanical properties, hydrogels need reinforcing with inorganic compounds. To overcome the main disadvantage, poor mechanical properties, many types of hydrogel nanocomposites were developed by including an inorganic nanometer-size layered-clay. Among the great family of layered clays, layered double hydroxides, so-called anionic clays have received a growing attention for designing of intercalated and exfoliated nanocomposites [13-15]. The most suitable method for designing intercalated and exfoliated nanocomposites is in-situ polymerization due to a better dispersion of polymer chains between clay sheets [16-19]. The direct growing of polymer between clay layers lead to increasing of interlayer spacing [20-22]. Furthermore, the dispersion degree depends on the nature of polymers. Hydrophobic polymers are naturally incompatible with this type of clays. Generally, inorganic clays are hydrophilic species due to high number of hydroxyl groups which can be exposed around. However, the hydrophilic nature does not assure a high dispersion in water or polar solvents because the layers are closely packed. The high packaging degree represents an entropic barrier for solvents molecules diffusing into interlayer gaps [22]. It is known from the literature [23-26], that a modifying agent has a role for interlayer space expansion, decreasing of interlayer strong attractive forces and increasing of chemical compatibility with the polymer matrix. These favorable achievements were assured by organic modifying agents with an alkyl long chain. The increasing of the distance between layers is directly related to the length of the alkyl chain by the possibility of adopting of a higher packing density [27-28]. In this paper, we extend a critical view over chemical compatibility increasing of the organic modifying agent within polymer chains. A closer chemical structure of the agent with polymer structure chain in terms of identical functional groups could lead to better compatibility due to generating specific interactions. Furthermore, nanocomposite hydrogels with modified inorganic crosslinkers exhibit higher mechanical strength and toughness comparative with classical cross-linkers [29-31].

Designing of these types of cross-linkers involves the modification of inorganic nanoparticles (nanoclays, silica, titania, graphene oxide, carbon nanotubes, etc.) with specific active groups such as double bonds or reactive groups such as amino, carboxyl, hydroxyl etc., which can be cured [20, 32-35]. In this case, the system functionality is higher and cross-linkers bridge more polymer chains with different lengths. This high functionality is assured by the high specific surface area (high ratio surface/volume). The high specific surface area allows attaching a high number of free-end functional groups during the modification.

This fact explains high number of connections of the cross-linkers with polymer chains around. In case of mechanical stress, the portion of short chains can be fractured first and the long chains can resist and assure the nanocomposite hydrogel elasticity [29].

Furthermore, this modified inorganic nanoparticles acts not only as cross-linkers but as reinforcing agents and exhibit extraordinarily mechanical and thermal properties to the nanocomposite hydrogels even at low content ( $\max$. 5\%) [31].

This papers reports the obtaining of a novel type of polymer nanocomposite hydrogels based on modified LDH clay.

\section{Experimental part \\ Materials}

The raw materials such as acrylamide monomer, $N, N^{\prime}$ methylenebisacrylamide, $\mathrm{Al}\left(\mathrm{NO}_{3}\right)_{3} .9 \mathrm{H}_{2} \mathrm{O}, \mathrm{Mg}\left(\mathrm{NO}_{3}\right)_{2}$. $6 \mathrm{H}_{2} \mathrm{O}$, potassium persulfate, sodium dodecyl sulfate (SDS), 3-(Trimethoxysilyl) propyl methacrylate (ATPM), hexadecyltrimethylammonium bromide (CTAB) and sodium hydroxide were supplied by Sigma Aldrich. 
Obtaining of modified layered double hydroxide (LDH-SDS)

The dodecyl sodium sulfate modified mineral clay (LDHSDS) was obtained by a precipitation method according to Tao, Q., et al [23]. The solutions of $\mathrm{Mg}\left(\mathrm{NO}_{3}\right)_{2}, 6 \mathrm{H}_{2} \mathrm{O}$ and $\mathrm{Al}\left(\mathrm{NO}_{3}\right)_{3} .9 \mathrm{H}_{2} \mathrm{O}$ were obtained in and added over a solution of $\operatorname{SDS}^{3}(4 \mathrm{~g})^{2}$ and $\mathrm{NaOH}$ under stirring. The obtained precipitate was filtered and properly washed with hot water. The washed precipitate was left to dry at room temperature about one day and used for further synthesis.

\section{Obtaining of modified layered double hydroxide (LDH- ATPM)}

The ATPM modified mineral clay (LDH-ATPM) was obtained by a co-precipitation method from LDH-SDS. The LDH-SDS precipitate and cation hexadecyltrimethylammonium bromide were added in a 1:1 ratio and dispersed in dichloromethane solvent. The suspension was purged with nitrogen for oxygen removing and the modifying agent ATPM was added (3:1 ratio with LDHSDS). The mixture was refluxed at $50^{\circ} \mathrm{C}$ for 2 days. The obtained precipitate was washed with dichloromethane for SDS and CTAB removing.

\section{Preparation of polyacrylamide/LDH-ATPM nanocomposite hydrogels}

The nanocomposite hydrogels were obtained by in situ radical polymerization of acrylamide monomer in the presence of LDH-ATPM modified clay. First three aqueous solutions of acrylamide with $15 \%$ concentration were obtained. In the second step the LDH-ATPM was added in monomer solutions in a 1, 3 and $5 \%$ ratio (w/v) and sonicated for $30 \mathrm{~min}$. For the starting of polymerization the initiator and cross-linking agent, potassium persulfate and respectively $N, N^{\prime}$-methylenebisacrylamide (MBA) were added. The reaction mixtures were put in glass matrix and heated at $60^{\circ} \mathrm{C}$ for $72 \mathrm{~h}$. The polymerization reaction started at different period for the three-nanocomposite mixture, depending on the LDH-ATPM amount. No polymerization reaction was observed for LDH-ATPM concentration higher than $5 \%$, probably because at high amount the modified clay acts as a reaction retarder by stabilization of free radical or acts even as reaction inhibitor. After the polymerization, the LDH-ATPM nanocomposite samples were placed in distilled water for 3 days for purification and monomer extraction. The obtained nanocomposite samples were denoted as: PAA/LDH-ATPM 1\%, PAA/LDHATPM 3\%, PAA/LDH-ATPM 5\%.

\section{Characterization}

FTIR spectra of the modified PAA/LDH-ATPM and PAA/ LDH-SDS were recorded on a Bruker Vertex 70 FT-IR spectrophotometer using Attenuated total reflectance (ATR) accessory. FT-IR spectrophotometer used 32 scans and a resolution of $4 \mathrm{~cm}^{-1}$ in mid-IR region $4000-600 \mathrm{~cm}^{-1}$.

The X-Ray diffraction patterns obtained on PAA/LDHATPM composite hydrogels were carried out with a Panalytical X'PERT MPD X-ray Diffractometer, in the range $2 \theta=10-80$. An X-ray beam characteristic to $\mathrm{Cu} K \alpha$ radiation was used $(\lambda=1.5418 \AA)$.

The PAA/LDH-ATPM nanocomposite samples were subjected to morphological characterization by transmission electron microscopy (TEM) using a TECNAI F30 G² S-TWIN microscope operated at $300 \mathrm{kV}$ with Energy Dispersive X-ray Analysis (EDAX) facility.

The mechanical evaluation of the nanocomposite samples (specimens with $10 \mathrm{~mm}$ diameter and $5 \mathrm{~mm}$ height) was carried out by compression tests. Mechanical tests were done using an Instron 2519-107 Universal test machine equipped with a $5 \mathrm{kN}$ load cell. The measurements were achieved at room temperature with a compression rate of $1 \mathrm{~mm} / \mathrm{min}$.

Rheological measurements were run with $20 \mathrm{~mm}$ diameter parallel plates geometry using a Kinexus Pro Malvern rotational rheometer with a temperature control unit.

The nanocomposite samples with the proper diameter were placed on the plate and the test took place at $37^{\circ} \mathrm{C}$.

$X$-ray photoelectron spectroscopy (XPS) spectra of LDHSDS and LDH-silane were acquired to evaluate the modification of hydroxyl group of LDH with modifier agent ATPM by condensation reactions.

\section{Results and discussions}

FTIR investigation

Modified LDH-ATPM characterization

To reveal the modification of LDH-SDS clay with a novel modifying agent, FTIR-ATR analysis was employed. The LDH-SDS modification assumes the replacement of sodium dodecyl sulfate agent (SDS) with 3-(trimethoxysilyl) propyl methacrylate agent (ATPM) in the presence of hexadecyl trimethyl ammonium bromide salt (CTAB). The SDS replacement assumes the presence of a cationic structure for extraction considering that sodium dodecyl sulfate is an anionic structure. The bromide anion remains trapped inside to compensate the positive charges of the LDH layers. The spectra of LDH-SDS clay (fig.1) reveal the presence of sodium dodecyl sulfate by the main peak at $1628 \mathrm{~cm}^{-1}$ characteristic for $\mathrm{SO}_{2}$ of the sulfate unit.

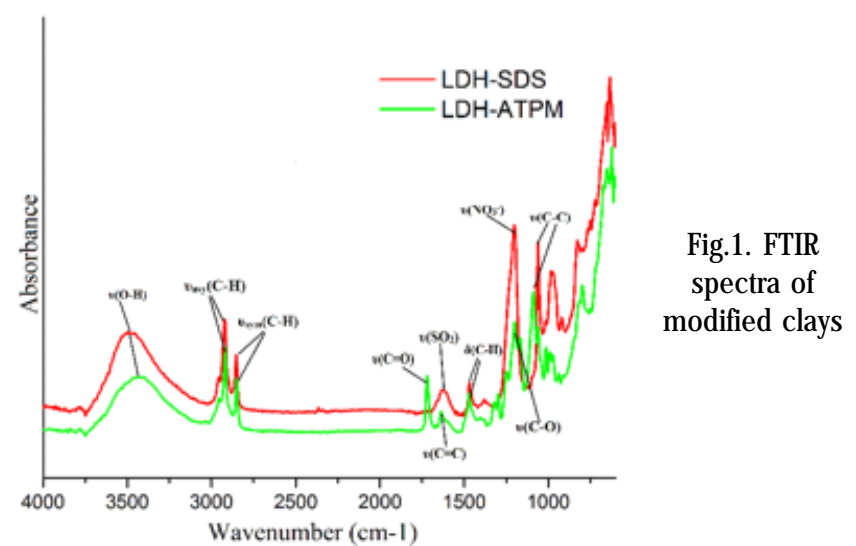

The presence of ATPM is assured by the main peaks at $1720 \mathrm{~cm}^{-1}$ and $1636 \mathrm{~cm}^{-1}$ characteristic for carbonyl group $(C=0)$, respectively carbon-carbon double bond $(C=C)$. The other spectra peaks, $\left(v_{0} \mathrm{OH}\right)$ at $3434 \mathrm{~cm}^{-1},\left(v_{\mathrm{s}} \mathrm{C}-\mathrm{H}\right)$ at $2960 \mathrm{~cm}^{-1},\left(v_{\mathrm{C}} \mathrm{C}-\mathrm{H}\right)$ at $2918^{\text {as }} \mathrm{cm}^{-1},(\delta \mathrm{C}-\mathrm{H})$ at $1468^{\text {as }} \mathrm{cm}^{-1},(v$ $\mathrm{NO}_{3}^{-}$) at $123 \mathrm{Cm}^{-1}$ and ( $\mathrm{V} \mathrm{C}-\mathrm{O}$ ) at $1230 \mathrm{~cm}^{-1}$ are characteristic for both modified clays. The schematic representation of LDH-ATPM synthesis is show ed in figure 2.

\section{Reactions of the LDH-ATPM double bonds}

Mechanical properties in terms of mechanical strength or stretchability are influenced not only by physical interactions, but also by chemical reactions. As we have previously mentioned, the obtaining of chemical bonds is crucial for improvement of the mechanical properties. To highlight the reaction of double bonds of ATPM structure agent with acrylamide monomer, FTIR analysis was carried out. Figure 3 reveals spectra of polymer PAA, modified clay LDH-ATPM and nanocomposites.

FTIR spectra of modified clay shows two main peaks at $1720 \mathrm{~cm}^{-1}$ and $1636 \mathrm{~cm}^{-1}$ characteristic for carbonyl group $(C=0)$, respectively carbon-carbon double bond $(C=C)$ 


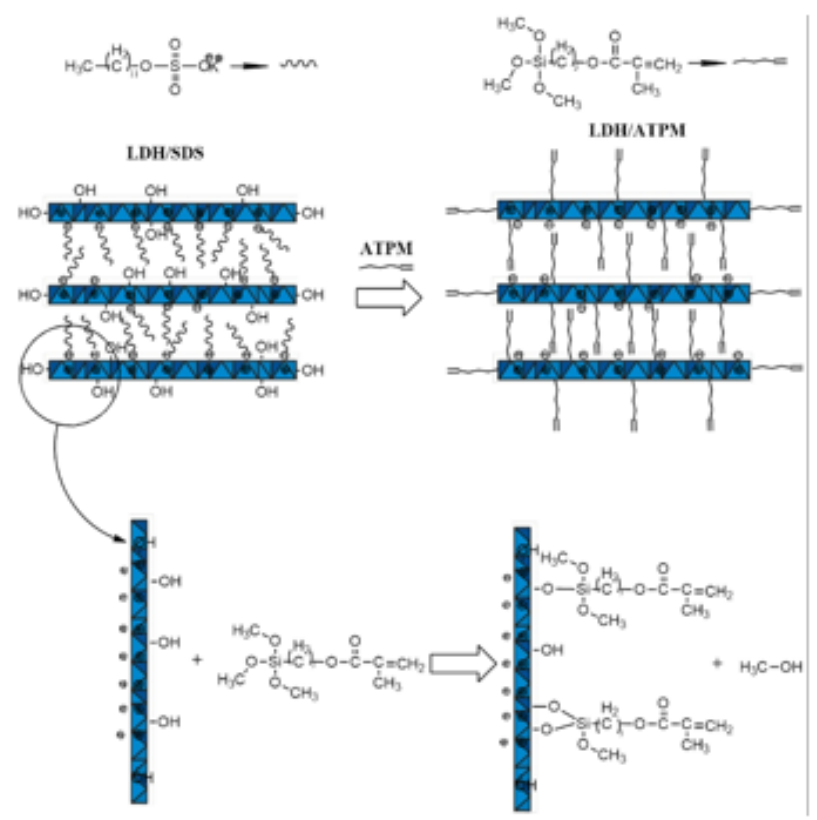

Fig.2. Condensation reaction of hydroxyl groups from LDH with methoxy group from ATPM

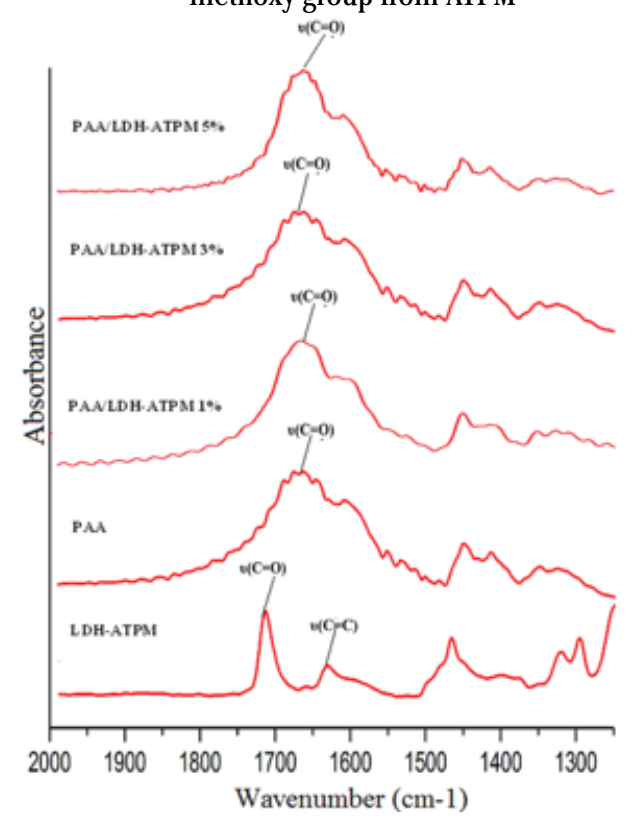

Fig.3. FTIR spectra of nanocomposite hydrogels and LDH-ATPM clay

that came from ATPM agent structure. PAA and nanocomposites show a peak at $1670 \mathrm{~cm}^{-1}$ characteristic for carbonyl group $(C=0)$ and a small shoulder at 1610 $\mathrm{cm}^{-1}$ specific for physical bonding of water molecules [36]

The absence of the carbon-carbon double bond $(C=C)$ characteristic peak at $1636 \mathrm{~cm}^{-1}$ from nanocomposites spectra may suggest that double bonds from ATPM were consumed in the reaction with monomer. Thereby, the modified clay induces the formation of the hydrogel netw orks by the cross-linking process besides usual crosslinker, MBA.

\section{$X$-ray photoelectron spectroscopy (XPS)}

XPS data confirmed both the interstitial character of doping with silane modifier and surface modification of $\mathrm{LDH}$ lattice. The values obtained for surface composition of LDH-silane samples are correlated well with the reaction mechanism that assume an increase of the Cls in the elemental composition. However, the lack of Si $2 p$ which confirmed the silane presence is a sign of interlayer modification. High-resolution spectra of 0 1s species of LDH-SDS and LDH-silane are shown in figure 4.
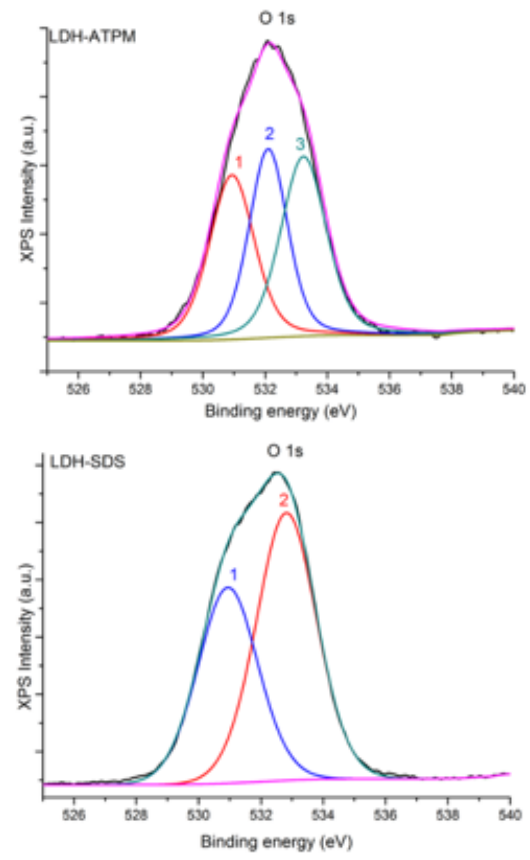

Fig.4. XPS spectra of LDH-SDS and LDHsilane (ATPM)

Both the 0 1s peak can be divided into secondary peaks through deconvolution, thus the 01 s secondary peak centered at about 530.9 corresponds to oxygen peak in hydroxyl bonding with inorganic lattice [37], while the one centered at $532.8 \mathrm{eV}$ is assigned to 0 is photoelectrons coming from the SDS moiety [38]. In case of silane modified LDH it can be noticed a shifting of these 01s secondary peaks as a sign of different interactions that occur around these species as for example the hydroxyl groups are interacting through hydrogen bonding to the newly hydrolyzed Si-OH moieties. Moreover, a new secondary 01s peak appears at higher binding energy $(533.16 \mathrm{eV})$, which can be assigned to O-Si species formed by the silane covalent bonding to the LDH lattices.

\section{Medium-frequency dynamic shear rheometry}

The dynamic mechanical behaviour of nanocomposite hydrogels was investigated by rheological measurements on water-swollen samples. To ensure that the measurements were performed in a linear viscoelastic domain, the strain was optimized. In this case, the elastic (storage) modulus Gtwas independent of strain amplitude and dependent only of frequency.

The samples were swollen for 2 days until they reach swelling equilibrium. The oscillatory tests were carried out at $37^{\circ} \mathrm{C}$ in a frequency range of 0.1 to $30 \mathrm{~Hz}$. The elastic modulus Gt shows higher values at high frequency for nanocomposite hydrogels with LDH-ATPM due to chemical networks of ATPM-modified clay (fig. 5).

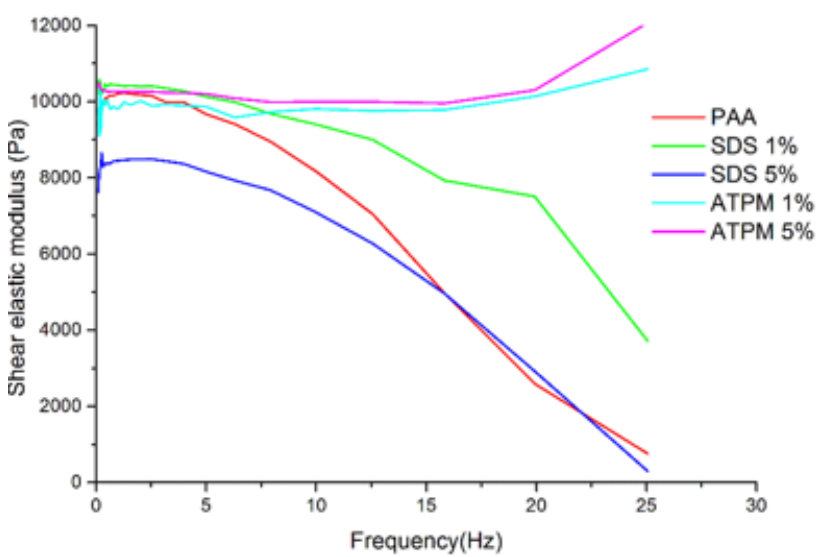

Fig.5. Elastic modulus versus frequency of swollen samples at equilibrium $\left(37^{\circ} \mathrm{C}\right)$ 
The nanocomposites with LDH-SDS and PAA hydrogel reveal lower elastic modulus Gt for high frequency and $\mathrm{G}^{\prime}$ increases with the decrease of frequency. This behaviour could be explained by the network covalent chains obtained by reaction of double bonds of modified-ATPM clay. Therefore, the double bonds of ATPM clay are responsible for the formation of the hydrogel networks besides classical cross-linker, MBA. The contribution of the clay covalent bonds to the hydrogel network formation leads to increasing of the elastically active chains by bridging more polymer chains with different lengths from surrounding area. This fact leads to the increase of the cross-linking density without decreasing the segmental mobility. The increasing of the elastically active chains from network ensures an almost linear elastic modulus Gt ranging from 0.1 to $30 \mathrm{~Hz}$ frequency.

\section{Mechanical analysis \\ Compression tests}

The nanocomposite hydrogel samples were subjected to mechanical stress to reveal the mechanical strength improvement. As shown in figure 6 and table 1, the nanocomposite samples display high increase of the compression strength compared to conventional samples with classic organic cross-linker.

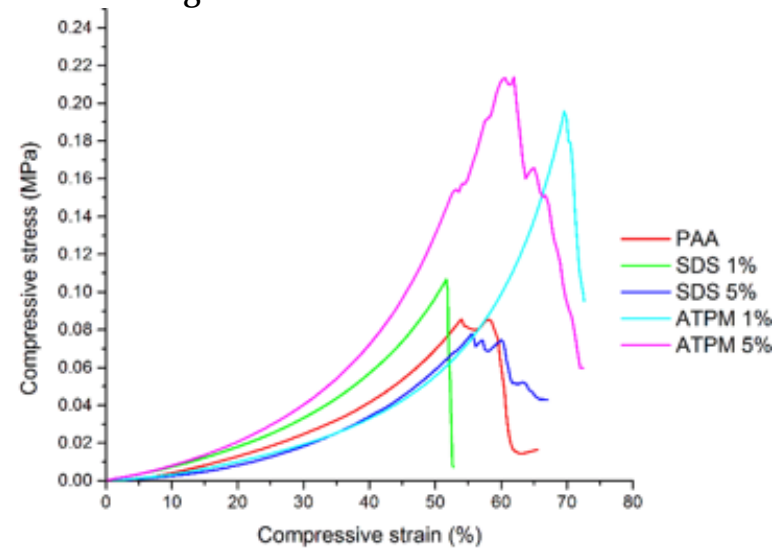

Fig. 6. Compression tests. Stress-strain curves for nanocomposite samples

The PAA control sample shows a compression strength at break of about $88 \mathrm{kPa}$, in the same range with PAA/ LDH-SDS $1 \%$ and PAA/LDH-SDS $5 \%$. This fact could be explained by the poor dispersion of the LDH-SDS into polymeric matrix. Modification of the crude LDH with sodium dodecyl sulfate is not enough to ensure the compatibility with the clay in polyacrylamide polymeric system. Improved mechanical properties of PAA/LDHATPM could be explain by the action of two factors, first, a better compatibility of the LDH-ATPM with the polymeric system and, secondly, the contribution of the ATPM agent double bonds to the cross-linking process. These factors lead to increasing of mechanical strength by duplicate compression strength values for PAA/LDH-ATPM $1 \%$ and PAA/LDH-ATPM 5\%. The increasing amount of LDH-ATPM from 1 to $5 \%$ ensures a small improvement of compression strength values probably because the system equilibrium is between these two values. The system equilibrium ensures a maximum dispersion degree of the modified clay, bigger amount of modified clay does not involve the increase of the mechanical strength.

\section{$X$-Ray diffraction analysis (XRD)}

The XRD patterns (fig.7) correspond to the main peak of the crystalline phase from modified clays and hydrogel nanocomposites with different clay ratios.
Table 1

VALUES OF THE COMPRESSION STRENGTHS FOR PAA AND NANOCOMPOSITE SAMPLES

\begin{tabular}{|l|c|c|}
\hline \multicolumn{1}{|c|}{ Sample } & $\begin{array}{c}\text { Compression } \\
\text { strength at break } \\
(\mathrm{kPa})\end{array}$ & Std. dev. \\
\hline PAA & 88 & 2.02 \\
\hline PAA/LDH-SDS 1\% & 110 & 3.12 \\
\hline PAA/LDH-SDS 5\% $\%$ & 82 & 2.83 \\
\hline PAA/LDH-ATPM 1\% & 208 & 3.14 \\
\hline PAA/LDH-ATPM1\% & 219 & 3.08 \\
\hline
\end{tabular}

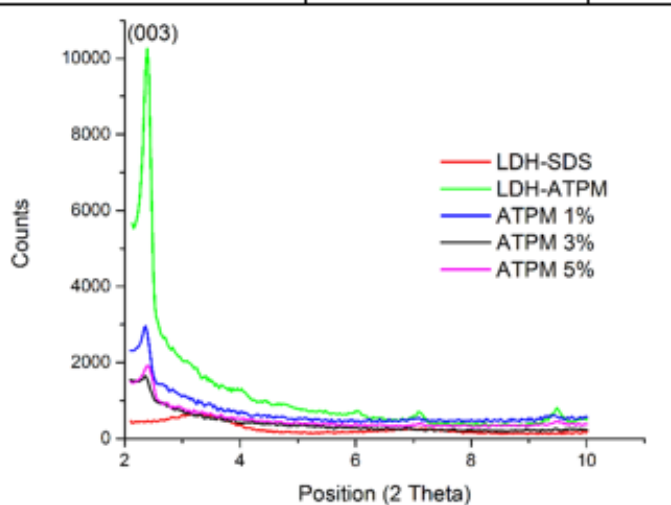

Fig.7. XRD diffractograms for modified clays and nanocomposites

LDH-SDS shows a specific peak at $2 \theta$ angle of 3.03 with an interlayer distance about 29.11 Angstrom. This prominent peak shows an orientation along (003) plane in all nanocomposite samples. No other peaks were detected, revealing a high purity of the modified clay. A decrease of the $2 \theta$ angle for modified LDH-ATPM at a value of 2.04 assumes modification of the interlayer distance at higher values. This modification is sustained by the interlayer distance measurement that reveals an increasing at 43.32 Angstrom (table 2). The increase of the interlayer distance is directly related to the presence of ATPM agent between clays sheets. This fact suggests that ATPM agent also decreases the interlayer strong attractive physical forces. Furthermore, a decrease of the clay crystalline specific peak value and increase of the interlayer distance appear for the nanocomposites as well. These results suggest the penetration of the macromolecular chains into clay layers due to a better compatibility with modifying agent and a better dispersion. The penetration of the macromolecular chains into interlayer spaces leads to the obtaining of the hydrogel nanocomposite intercalated and exfoliated structures.

Table 2

XRD PARAMETERS, INTERLAYER DISTANCES AND DIFFRACTION ANGLES

\begin{tabular}{|l|c|c|}
\hline \multicolumn{1}{|c|}{ Sample } & $\begin{array}{c}\text { Distance } \\
\text { (Angstrom) }\end{array}$ & Angle 2 $\theta$ \\
\hline LDH-SDS & 29.11 & 3.03 \\
\hline LDH-ATPM & 43.32 & 2.04 \\
\hline PAA/LDH-ATPM 1\% & 37.2 & 2.37 \\
\hline PAA/LDH-ATPM 3\% & 37.2 & 2.37 \\
\hline PAA/LDH-ATPM 5\% & 36.5 & 2.4 \\
\hline
\end{tabular}

Transmissison electron microscopy (TEM) analysis

TEM morphological characterization was employed to reveal the ordering level of the modified ATPM clays within polymeric matrix and to support the XRD results. TEM images highlight the crystalline planes of the modified clay and nanocomposites with different amount of LDH-ATPM (fig.8). 


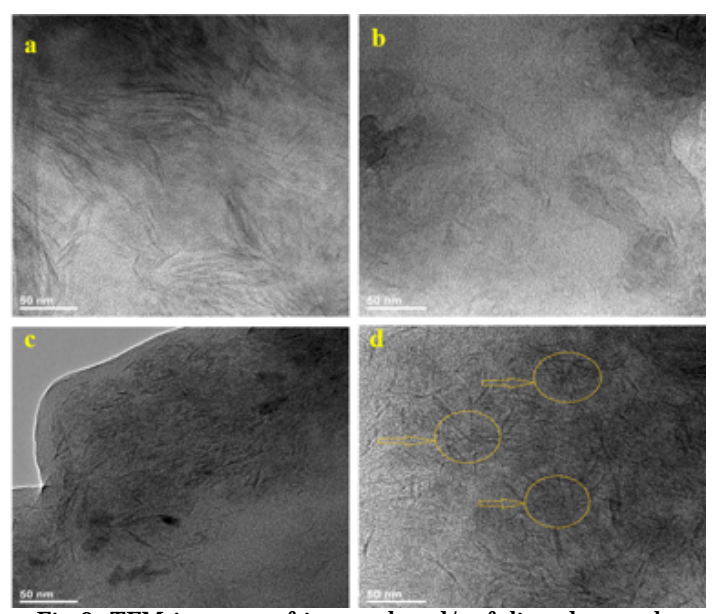

Fig.8. TEM images of intercalated/exfoliated samples: a) LDH-ATPM; b) PAA/LDH-ATPM 1\%; c) PAA/LDH-ATPM 3\%; d) PAA/ LDH-ATPM

In modified LDH-ATPM images can be noticed the general aspect of an agglomerate of layered clay nanoparticles with a random distribution. This agglomerate aspect is given by the oriented crystalline planes of the functionalized clay. The clay layers are held together by interlayer forces in crystalline structures. These results are also confirmed by the XRD patterns. Nanocomposites with $1 \%$ LDH-ATPM shows layered clay nanoparticles dispersed into polymeric matrix, but in a smaller proportion due to low concentration. This type of distribution could lead to higher ratio of intercalated structures over the exfoliate ratio. This type of behavior assumes such structures where clay layers and polymeric chains alternate.

Results are sustained by XRD investigations that show an increased clay interlayer distance due to penetration of polymeric chains between clay layers. Nanocomposite with 3\% LDH-ATPM reveals a disordered orientation of the clay layers into polymeric matrix and an important amount of agglomerated clay nanoparticles. Such arrangement suggests the obtaining of intercalated structures for agglomerate layers and exfoliated structures for dispersed clay layers. In this situation, the intercalated/exfoliated structures are probably in close ratio. These results are also sustained by XRD diffraction patterns which highlight the intercalated areas by increasing of interlayer distance. Nanocomposites with 5\% LDH-ATPM assumes the obtaining of exfoliated structures in a higher ratio against nanocomposites with lower LDH-ATPM concentrations. This fact is sustained by the random and complete distribution of the modified clay layers into polymeric matrix. Exfoliated areas are highlighted by colored circles. In this case, XRD results cannot sustain the morphological analyses because in exfoliated structures the clay layers are no more ordered in crystalline phases. The areas with intercalated structures are presented in figure 9.

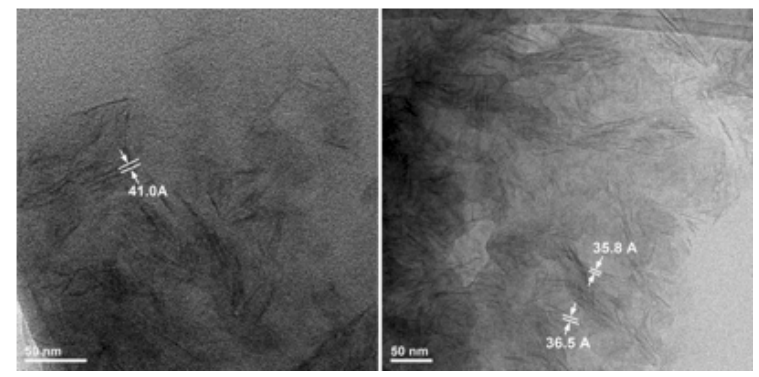

Fig.9. Interlayer distances for nanocomposite hydrogel with $5 \%$ LDH-ATPM measured by TEM
There are measured some interlayer distances to fit the diffraction analysis. Therefore, the interlayer distances measured by TEM analysis match with XRD measurements, with interlayer distances within 35-41 Angstrom.

\section{Conclusions}

Novel organic/inorganic hybrid nanocomposites were developed by in situ polymerization of acrylamide in the presence of modified clay in an aqueous solution system. The free radical polymerization leads to design of novel soft polymeric networks with exfoliated structures. The physico-chemical characterization by FTIR assumes the modification of LDH-SDS clay with a new ATPM double bond agent. Moreover, the XPS analysis highlights the modification mechanism by covalent bonds 0 -Si which ensures a higher stability for modifying agent. The modification increases the dispersion degree of modified clay into aqueous acrylamide system by its intrinsic structure close to monomer chemical structure. A higher dispersion allows a random and complete distribution of the clay layers into monomer phase and further, polymer phase. Furthermore, the ATPM agent takes part to netw ork formation by its double bonds reaction. The modification of LDH-SDS is also sustained by the X-Ray Diffraction results. The network structure of hybrid hydrogels ensures the enhance of mechanical properties by increasing of elastically active chains density. The enhanced mechanical properties are sustained by compression tests and dynamic shear rheometry analysis. The morphological characterization by TEM highlights the exfoliation process of the modified clay layers into polymeric matrix. The exfoliation process leads to exfoliated structures with greater mechanical properties due to randomly distribution of the layers, which assure the same resistance regardless of the force direction of action.

Acknowledgements:This work was supported by a grant of the Romanian Ministery of Research and Innovation, CCCDI - UEFISCDI, project number PN-III-P1-1.2-PCCDI-2017-0407/39PCCDI-2018, within PNCDI III.

\section{References}

1. KAMATA, H., AKAGI, Y., KAYASUGA-KARIYA, Y., CHUNG, U.-I., SAKAI, T., Science, 343, no. 6173, 2014, p. 873.

2. ITAGAKI, H., KUROKAWA, T., FURUKAWA, H., NAKAJIMA, T., KATSUMOTO, Y., GONG, J.P., Macromolecules, 43, no. 22, 2010, p. 9495.

3. KEPLINGER, C., SUN, J.-Y., FOO, C.C., ROTHEMUND, P., WHITESIDES, G.M., SUO, Z., Science, 341, no. 6149, 2013, p. 984.

4. ZHAO, X., Soft Matter, 10, no. 5, 2014, p. 672.

5. HAIDER, M., MEGEED, Z., GHANDEHARI, H., J ournal of Controlled Release, 95, no. 1, 2004, p. 1.

6. JEONG, B., GUTOWSKA, A., Trends in Biotechnology, 20, no. 7, 2002, p. 305.

7. KOPECEK, J., European J ournal of Pharmaceutical Sciences, 20, no. 1,2003, p. 1

8. LANGER, R., TIRRELL, D.A., Nature, 428, 2004, p. 487.

9. MEGEED, Z., CAPPELLO, J., GHANDEHARI, H., Advanced Drug Delivery Reviews, 54, no. 8, 2002, p. 1075.

10. SERAFIM, A., OLARET, E., CECOLTAN, S., BUTAC, L.M., BALANUCA, B., VASILE, E., GHICA, M., STANCU, I.C., Mat. Plast., 55, no. 1, 2018, p. 68.

11. GHEBAUR, A., GAREA, S.A., CECOLTAN, S., IOVU, H., Mat. Plast., 54, no. 1, 2017, p. 1.

12. DRAGUSIN, D.M., CURTI, F., CECOLTAN, S., SARGHIUTA, D., BUTAC, L.M., VASILE, E., MARINESCU, R., STANCU, I.C., Mat. Plast., 54, no. 2, 2017, p. 207.

13. RIVES, V., M. DEL ARCO, MARTIN, C., Applied Clay Science, 88-89, 2014, p. 239. 
14. VARGHESE, S., ELISSEEFF, J.H., Musculoskeletal Tissue Engineering, in: C. Werner (Ed.), Polymers for Regenerative Medicine, Springer Berlin Heidelberg, Berlin, Heidelberg, 2006, p. 95.

15. GALATEANU, B., RADU, I.C., VASILE, E., HUDITA, A., SERBAN, M.V., COSTACHE, M., IOVU, H., ZAHARIA, C., Mat. Plast., 54, no. 4, 2017, p. 659.

16. LEROUX, F., BESSE, J.-P., Chemistry of Materials, 13, no. 10, 2001, p. 3507.

17. PAUL, M.A., ALEXANDRE, M., DEGEE, P., CALBERG, C., JEROME, R., DUBOIS, P., Macromolecular Rapid Communications, 24, no. 9, 2003, p. 561.

18. PAUL, M.A., DELCOURT, C., ALEXANDRE, M., DEGEE, P., MONTEVERDE, F., RULMONT, A., DUBOIS, P., Macromolecular Chemistry and Physics, 206, no. 4, 2005, p. 484.

19. TAVIOT-GUEHO, C., LEROUX, F., In Situ Polymerization and Intercalation of Polymers in Layered Double Hydroxides, in: X. Duan, D.G. Evans (Eds.), Layered Double Hydroxides, Springer Berlin Heidelberg, Berlin, Heidelberg, 2006, pp. 121.

20. VIEILLE, L., MOUJAHID, E.M., TAVIOT-GUEHO, C., CELLIER, J., BESSE, J.-P., LEROUX, F., J ournal of Physics and Chemistry of Solids, 65, no. 2, 2004, p. 385.

21. WANG, G.-A., WANG, C.-C., CHEN, C.-Y., Polymer, 46, no. 14, 2005, p. 5065.

22. BIKIARIS, D.N., Polymer Degradation and Stability, 98, no. 9, 2013, p. 1908.

23. TAO, Q., HE, H., FROST, R.L., YUAN, P., ZHU, J., Applied Surface Science, 255, no. 7, 2009, p. 4334.

24. CHIANG, M.-F., WU, T.-M., Composites Science and Technology, 70, no. 1, 2010, p. 110.
25. DEL HOYO, C., Applied Clay Science, 36, no. 1, 2007, p.103.

26. LEROUX, F., DALOD, A., HENNOUS, M., SISTI, L., TOTARO, G., CELLI, A., COEHLO, C., VERNEY, V., Applied Clay Science, 100, 2014, p. 102.

27. MEYN, M., BENEKE, K., LAGALY, G., Inorganic Chemistry, 29, no. 26, 1990, p. 5201.

28. M. MEYN, K. BENEKE, G. LAGALY, Inorganic Chemistry, 32, no. 7, 1993, p. 1209.

29. WANG, Q., GAO, Z., Journal of the Mechanics and Physics of Solids, 94, 2016, p. 127.

30. PARK, A.Y., KWON, H., WOO, A.J., KIM, S.J., Advanced Materials, 17, no. 1, 2005, p. 106.

31. HU, Z., CHEN, G., Advanced Materials, 26, no. 34, 2014, p. 5950.

32. CARLSSON, L., ROSE, S., HOURDET, D., MARCELLAN, A., Soft Matter, 6, no. 15, 2010, p. 3619.

33. HARAGUCHI, K., Science, 11, no. 3, 2007, p. 47-54.

34. HARAGUCHI, K., Polymer J ournal, 43, 2011, p. 223.

35. WILLIAMS, G.A., ISHIGE, R., CROMWELL, O.R., CHUNG, J., TAKAHARA, A., GUAN, Z., Advanced Materials, 27, no. 26, 2015, p. 3934.

36. MAGALHAES, A.S.G., ALMEIDA NETO, M.P., BEZERRA, M.N., RICARDO, N.M.P.S., FEITOSA, J.P.A., Quimica Nova, 35, 2012, p. 1464. 37. PENG, F., WANG, D., TIAN, Y., CAO, H., QIAO, Y., LIU, X., Scientific Reports, 7, no. 1, 2017, p. 8167.

38. ZHANG, F., ZHANG, C.-L., SONG, L., ZENG, R.-C., CUI, L.-Y., CUI, H.-Z., Acta Metallurgica Sinica (English Letters), 28, no. 11, 2015, p. 1373.

$\overline{\text { Manuscript received: } 11.07 .2018}$ 